\title{
The frequency of consanguineous marriage among British Pakistanis
}

\author{
A DARR AND B MODELL \\ From the Department of Obstetrics and Gynaecology, Faculty of Clinical Sciences, University College \\ London.
}

SUMmARY An enquiry answered by 100 randomly selected British Pakistani mothers in the postnatal wards of two hospitals in West Yorkshire showed that 55 were married to their first cousins, while in only 33 cases had their mother been married to her first cousin. This suggests an increasing rate of consanguineous marriage in this relatively small group, by contrast with the decreasing rate observed in some other countries. The genetic implications merit further study.

Consanguineous marriage is common in many parts of the world, ${ }^{1}$ and in Pakistan and most Middle Eastern countries the custom is considered socially supportive. ${ }^{2}$ A high frequency of first cousin marriage among British Pakistanis has already been noted. ${ }^{3}$ We found that in 17 out of 18 British Pakistani families with thalassaemic children living in the Bradford area of Yorkshire, the parents were closely consanguineous. Table 1 summarises the marriage relationships in 15 families that were studied more closely. It was found that three families were also transmitting a second recessively inherited disorder (two cystic fibrosis and one maple syrup urine disease). Fig 1 illustrates the complex pattern of relationships that may occur. The present study was undertaken to relate these findings to the background frequency of consanguineous marriage amongst British Pakistanis.

Received for publication 8 December 1986 Revised version accepted for publication 6 April 1987.

\section{Methods}

With the permission of their obstetricians, 101 consecutive women of Pakistani origin admitted to the postnatal wards of St Luke's Hospital, Bradford and the Bradford Royal Infirmary were approached by a British Pakistani sociologist (AD) with the request for their cooperation in this study. When the objective, that is, to gather information on different marriage patterns, had been explained, all but one of the mothers agreed to a fuller discussion. These 100 women were interviewed in their mother tongue (Punjabi or Urdu). Basic details such as the mother's age were extracted from the obstetric notes, which also contain a slot for recording consanguinity. In each case a limited family tree was constructed. A full explanation and some delicacy were required, so each interview took on average 20 minutes.

The study was designed to see if the frequency of consanguineous marriage is changing with time, so

TABLE 1 Marriage relationships in 15 families of British Pakistani children with thalassaemia major.

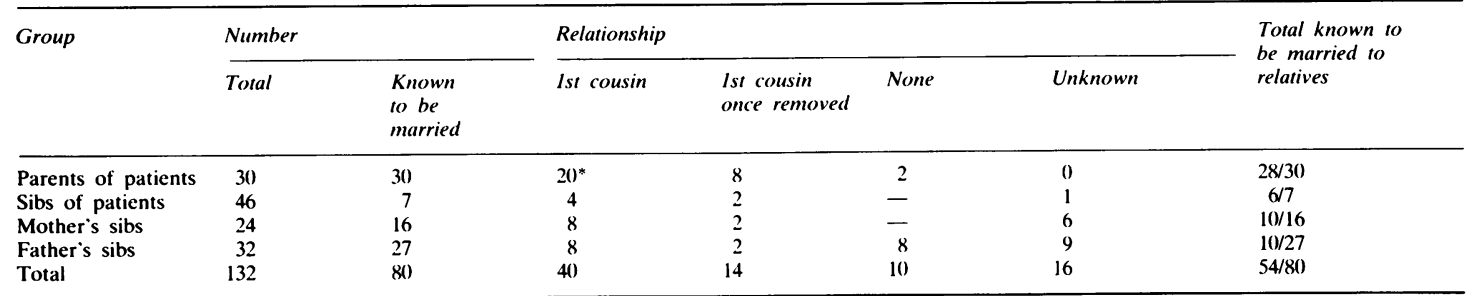

*One double first cousin. 


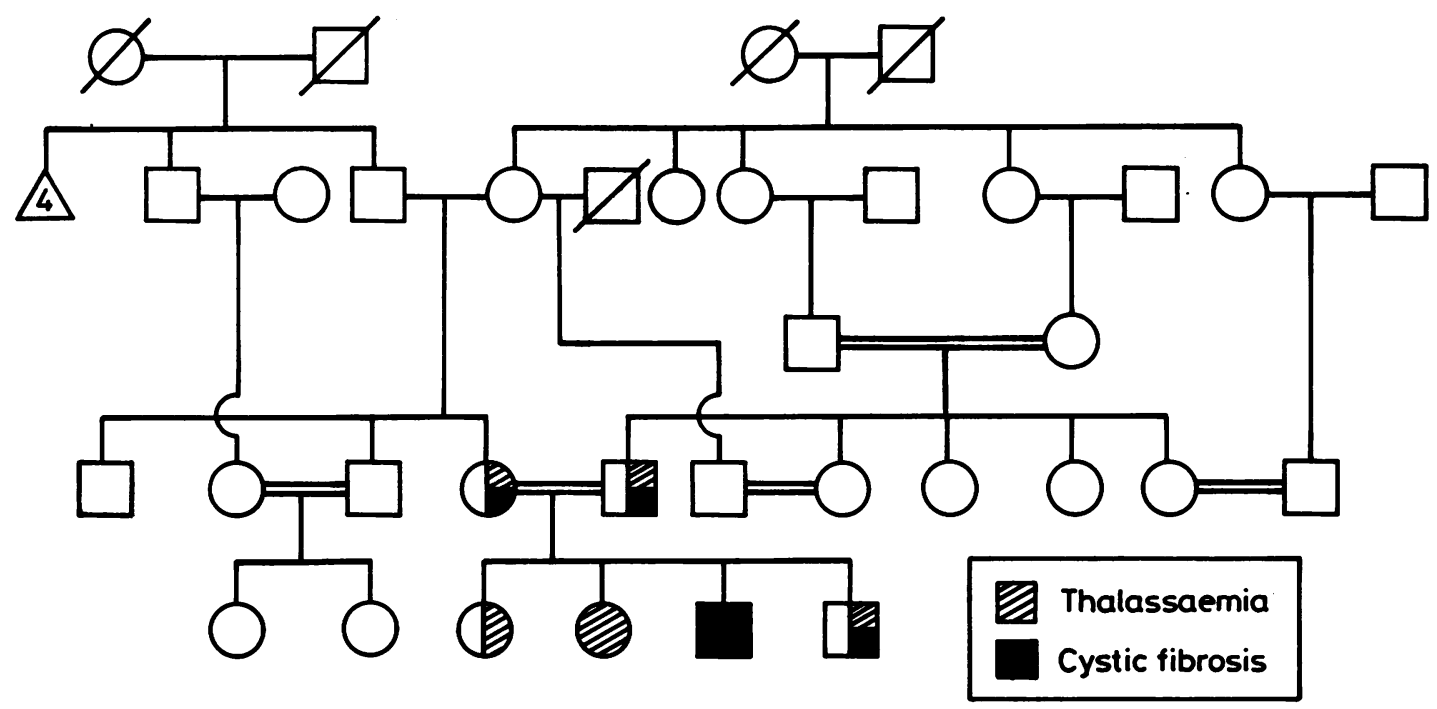

FIG 1 Family pedigree of a British Pakistani family transmitting both thalassaemia and cystic fibrosis. The first child of the presenting couple was a healthy carrier of thalassaemia trait; their second child had thalassaemia major, and the third cystic fibrosis. The thalassaemic child died following an attempted bone marrow graft from her mother, who was fully HLA compatible. The fourth child, who was born after a first trimester prenatal diagnosis for both disorders, is a healthy carrier of both thalassaemia and cystic fibrosis. ${ }^{4}$ The parents are first cousins once removed. Two of the father's sibs and one of the mother's sib are married, all to close relatives. This pattern of family relationships is common among Pakistanis, in both Pakistan and the UK.

each woman was asked: (1) if she and her husband had been related before marriage, and if so the exact degree of the relationship; (2) the degree of relationship, if any, between her own parents; and (3) the degree of relationship, if any, between the parents of her husband. The results were checked for correspondence with the information on consanguinity in the obstetric notes.

\section{Results}

The mothers were mostly young (fig 2), with an average age of 26 years. All were quite clear about their degree of relationship with their husband: 96 were sure of their own parents' degree of relationship but only 84 were sure of the degree of relationship of their husband's parents. The results are summarised in table 2 .

\section{THE PARENTS}

Fifty five of the women interviewed were married to first cousins. All four possible types of cousin marriage occurred, with the frequencies given in table 3. No double first cousin marriages were reported in this generation. Nine women were married to first cousins once removed, three to second cousins, and three to more distant relatives (one first cousin twice removed, one second cousin once removed, one third cousin). Thirteen were married within the 'Biraderi', a term describing the wider family group. Some of these husbands would be distant relatives, some relatives only by marriage, and some simply originating from the same locality and social group. Only 17 women definitely had completely unrelated husbands, but for genetic

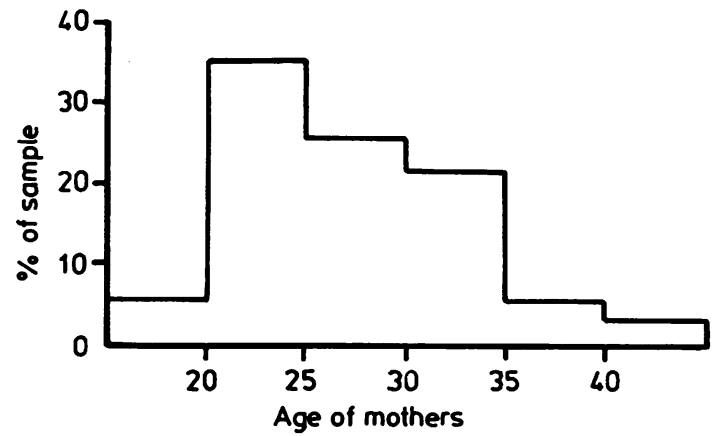

FIG 2 Age distribution of the 100 British Pakistani women interviewed in the postnatal wards in Bradford Royal Infirmary and St Luke's Hospital. 
TABLE 2 Relationship before marriage of 100 randomly selected British Pakistani couples interviewed postnatally and the relationship of their parents.

\begin{tabular}{|c|c|c|c|}
\hline \multirow[t]{2}{*}{ Relationship } & \multirow{2}{*}{$\begin{array}{l}\text { Parental } \\
\text { generation } \\
\text { No }(=\%)\end{array}$} & \multicolumn{2}{|c|}{ Grandparental generation } \\
\hline & & $\begin{array}{l}\text { Maternal } \\
\text { No }(=\%)\end{array}$ & $\begin{array}{l}\text { Paternal } \\
\text { No }(=\%)\end{array}$ \\
\hline Unknown & 0 & 4 & 16 \\
\hline Double first cousins & 0 & 2 & 3 \\
\hline First cousins & 55 & 31 & 24 \\
\hline Other close relative & 15 & 9 & 12 \\
\hline Unrelated & 17 & 30 & 24 \\
\hline Total & 100 & 100 & 100 \\
\hline Coefficient of inbreeding ( $\min$ value) & $0 \cdot 0375$ & $0 \cdot 027$ & - \\
\hline
\end{tabular}

TABLE 3 Relative frequency of the different types of first cousin marriage.

\begin{tabular}{lc}
\hline Woman married to & No \\
\hline Mother's brother's son & 20 \\
Father's brother's son & 17 \\
Father's sister's son & 11 \\
Mother's sister's son & 7 \\
Total & 55 \\
\hline
\end{tabular}

purposes, 30 of the 100 couples could be considered as unrelated.

The hospital notes contained information on consanguinity in only 59 cases and there were 16 errors. Six unrelated couples (three in the Biraderi) were described as related, two related couples were described as unrelated, and eight relationships were wrongly described. One mother married to her first cousin confessed to having told the nurse they were unrelated "because they frown on you and question you if you are married to your cousin".

\section{THE GRANDPARENTS}

Naturally enough, more information was available for the respondent's parents than for her parents in law. There is no reason to think that there would be differences between the two sets of grandparents, and to eliminate the uncertainties of interpreting the larger number of 'unknown' and 'closely related' responses for the parents in law, the more complete and reliable figures for the respondent's own parents were used. In this group of grandparents there was a maximum of 33 first cousin marriages, with more marriages (24) among the Biraderi and more (30) to unrelated partners. The four couples whose relationship was unknown are more likely to have been unrelated than closely related, but this has not been assumed here.

Table 4 shows that the pattern of inbreeding in the population is not uniform: unrelated couples are more likely to have unrelated parents, while married couples of first cousins more often have closely related parents.

\section{Discussion}

The frequency of consanguineous marriage is thought to be falling in most populations as a result of social change and increased mobility. For $\bigcirc$ instance, in Japan it decreased from $13 \%$ in urban $D$ and $21 \%$ in rural areas to $2.9 \%$ in urban and $4.3 \%$ in

TABLE 4 Relationship of the parents of 17 unrelated couples compared with 55 couples of first cousins. (Information on parents of both partners is included.)

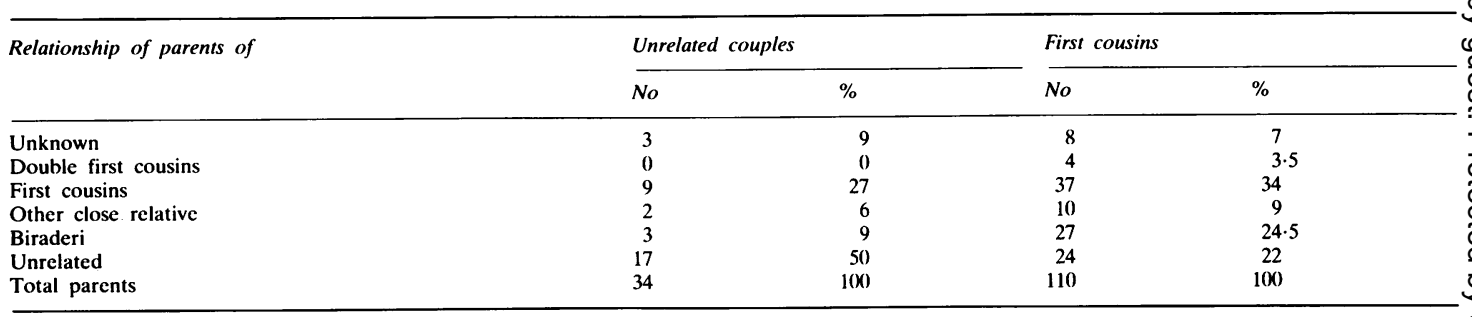


rural areas between 1947 and $1972 .^{5}$ By contrast, among British Pakistanis the coefficient of inbreeding seems to have increased in a single generation from about 0.024 to 0.0375 , a figure approaching the highest reported for human populations. ${ }^{6}$

In a study of congenital heart disease among British Pakistanis, $88 \%$ of the parents of children with complex lesions were first cousins, compared with $55 \%$ of the parents of children with all other types of cardiac lesions. ${ }^{3}$ The latter figure agrees with our findings for young British Pakistani couples, and suggests a minimal contribution of recessive inheritance to non-complex cardiac lesions in this population. However, the investigators found only $40 \%$ cousin marriage on questioning 300 Asian passers-by in the markets of four northern English towns. It is likely that the difference between their results and ours was due to a mixture of generations among the passers-by. Since change with time may be so rapid, the age of the respondents must always be taken into acount when investigating consanguinity.

An enquiry among 900 women in hospital in Lahore, Pakistan, in 1983 showed $36 \%$ first cousin marriages, $4 \%$ first cousin once removed, $8 \%$ second cousin, and 53\% unrelated (of which $25 \%$ were in the Biraderi). ${ }^{7}$ These figures are almost identical with those reported here for the grandparental generation (who married while in Pakistan), and support our conclusion that the frequency of close consanguineous marriage is increasing among British Pakistanis.

The causes of this trend in the UK were not investigated in the present study, but it probably follows from constraints imposed by migration. Pakistanis, like many other groups, consider it an important parental responsibility to find spouses for their children. They prefer to select someone they know well, to be sure that he or she has the qualities they appreciate and will make a caring partner. However, ethnic minorities face two problems: the limited availability of suitable persons in the restricted local community, ${ }^{8}$ and the fact that their circle of acquaintance in the country of origin tends to shrink within the limits of the extended family. Therefore, for groups with a tradition of consanguineous marriage, it is only natural for the choice of partner to fall progressively closer within the family circle.

It is possible that a similar trend exists among other ethnic minorities in Europe with a tradition of consanguineous marriage, for instance, people of North African origin in France and Belgium and people of Turkish origin in Germany and the Scandinavian countries.

The main genetic implication of consanguinity is an increase in the birth rate of homozygotes for recessively inherited Mendelian characteristics in relation to the gene frequency. Because this leads to accelerated loss of lethal recessives from the gene pool, the custom is thought to correct its pathological genetic effects with the passage of time. There is evidence to support this view from South India, where monogamous, close consanguineous marriage has been practised for thousands of years." However, traditional consanguineous marriage among Pakistanis goes back only to the popular adoption of Islam, mainly in the 16th and 17th centuries, so a major reduction in the frequency of recessively inherited lethal traits in the Pakistani population is as yet unlikely. Most paediatricians are aware of an increased frequency of genetic disorders among British Pakistanis, and an increased contribution of recessive inheritance to mental retardation $^{10}$ and complex cardiac lesions with situs ambiguus $^{5}$ has been noted in this population. Consanguinity may also contribute to the high perinatal mortality, ${ }^{11}$ since in their classical study of Japanese children, Schull and $\mathrm{Neel}^{12}$ found only a small effect of consanguinity on general parameters such as height or school performance, but there was a significant effect on the perinatal and childhood mortality. It appears that British Pakistanis are a group at high genetic risk.

In 1983, 353 000 citizens of the UK lived in households whose head had been born in Pakistan ${ }^{1.3}$ and $45 \%$ of them were less than 15 years old. The number of couples at risk is therefore substantial and will increase in the coming years, due to the rising frequency of consanguineous marriage and the young age structure of the population. The proportion of British Pakistani women in the age group at risk for chromosomal non-disjunctions, minimal at present (fig 2), is also likely to increase in the future. There is therefore every reason to spend the time and effort required to ensure that British Pakistanis are given adequate information and appropriate genetic counselling. It is even more important to avoid giving inappropriate advice. Consanguineous marriage has important social functions, compared with which its genetic consequences are relatively minor, and attempts to discourage it systematically on genetic grounds would certainly do more harm than good.

On the other hand, a consanguineous marriage pattern distributes the risk of bearing offspring with recessively inherited diseases inhomogeneously in the population, in family groups that may often be identified by the birth of the first affected child. Each index patient therefore marks a family cluster at high genetic risk and in principle it should be possible to deliver genetic counselling very effec- 
tively by following up the extended family. British Pakistani families usually understand and value genetic information, when they have several opportunities to discuss it in their own language with a trained counsellor (unpublished data). It is not yet clear whether they would incorporate it into the choice of a marriage partner, though it seems likely that some families with severe genetic problems might start to discourage further matings within the kindred. It has also become clear that though midtrimester prenatal diagnosis and selective abortion is not often accepted by British Pakistani couples, ${ }^{14}$ first trimester diagnosis by chorionic villus sampling is more acceptable. ${ }^{15}$

To develop a strategy for offering appropriate genetic help to British Pakistanis, it will be necessary to obtain more information on the epidemiology of genetic diseases in this group, and a major educational effort for both the population at risk and health professionals will be required. As a first step, draft information booklets for families and for health professionals are now available from the World Health Organization.*

We are grateful to $\mathrm{Mr} \mathrm{J} \mathrm{K}$ Clayton, Mr J E EytonJones, Mr J R Rand, Mr I Beck, and Mr D I M Farquharson, the obstetricians at Bradford, for giving us access to their patients. The work was supported by a 'small grant' from the UK Department of Health and sponsored by the World Health Organization. BM is a senior Wellcome Research Fellow.

Crown copyright 1987. No part of this article may be reproduced in any form or media without the permission of the Department of Health and Social Security. The support for this research was provided by the DHSS: the views expressed are those of the authors.

*Copies can be obtained from The Hereditary Discases Programme, WHO. Geneva, Switzerland.

\section{References}

1 Report of a WHO Advisory Group on Hereditary Diseases, Geneva, 3 to 5 October 1985. Unpublished WHO document HMG/AG/85.10.

2 Khlat M, Halabi S, Khudr A, Der Kaloustian VM. Perception of consanguineous marriages and their genetic effects among a sample of couples from Beirut. Am J Med Genet 1986;25: 299-306.

3 Gatrad AR, Read AP, Watson GH. Consanguinity and com- ڤे plex cardiac anomalies with situs ambiguus. Arch Dis Child $\vec{\circ}$ 1984;59:242-5.

4 Law HY, Stanier P, Williamson R, et al. Two unusual cases of $\overrightarrow{\vec{\omega}}$ first trimester prenatal diagnosis of cystic fibrosis using DNA probes. Prenat Diagn 1987;7:215-21.

$s$ Imaizumi Y, Shinozaki N. Frequency of consanguineous marriages in Japan: geographical variations. Jpn J Hum Genet 1984;29:381-5.

${ }^{6}$ Bodmer WF, Cavalli-Sforza LL. Genetics, evolution, and man. San Francisco: WH Freeman, 1976.

7 Shami SA, Zahida. Study of consanguineous marriages in the population of Lahore, Punjab, Pakistan. Biologia 1982;28: 1-15.

${ }^{8}$ Khan VS. The Pakistanis: Mirpuri villagers at home and in Bradford. In: Watson JL, ed. Between two cultures: migrants and minorities in Britain. Oxford: Blackwell, 1977.

9 Rao PSS, Inbaraj SG. Inbreeding effects on fertility and sterility in southern India. J Med Genet 1979;16:24-31.

10 Bundey S, Webb TP, Thake A, Todd J. A community study of severe mental retardation in the West Midlands and the import- $\infty$ ance of the fragile $\mathrm{X}$ chromosome in its aetiology. J Med Genet 1985;22:258-66.

11 (UK) Office of Population Censuses and Surveys. OPCS Series DH3 No 13

12 Schull WJ, Neel JV. The effects of inbreeding on Japanese children. New York: Harper and Row, 1956.

${ }^{13}$ Labour Force Survey 1983. Country of birth, ethnic origin, nationality and year of entry. OPCS Monitor 18.12.84. Ref LFS $84 / 2$ and PP1 84/5.

14 Modell B, Petrou M, Ward RHT, et al. Effect of fetal diagnostic testing on the birth-rate of thalassaemia in Britain. Lancet 1984 ii: $1383-6$.

is Old JM, Fitches A, Heath C, et al. First-trimester fetal diagnosis for haemoglobinopathies: report on 200 cases. Lancet 1986;ii: 763-8.

Correspondence and requests for reprints to Dr B Modell, Perinatal Centre, Ground Floor, Rayne Institute, University Street, London WC1E 6JJ. 